Article

\title{
Symmetric Performance Analysis for Mechanical Properties of Sustainable Asphalt Materials under Varying Temperature Conditions: An Application of DT and NDT Digital Techniques
}

\author{
Muhammad Kashif Anwar ${ }^{1}$, Syyed Adnan Raheel Shah ${ }^{1, *}$, Abdullah Naveed Sadiq ${ }^{1}$, \\ Muhammad Usman Siddiq ${ }^{1}$, Hassam Ahmad ${ }^{1}$, Saqib Nawaz ${ }^{1}$, Asif Javead ${ }^{1}$, \\ Muhammad Hasnain Saeed ${ }^{1}$ and Ahsan Rehman Khan ${ }^{2}$ \\ 1 Department of Civil Engineering, Pakistan Institute of Engineering and Technology, Multan 66000, Pakistan; \\ kashifanwar723@gmail.com (M.K.A.); abdullahnaveed200@gmail.com (A.N.S.); \\ usmansiddiq723@gmail.com (M.U.S.); hassamahmad04@gmail.com (H.A.); \\ Saqibktk25397@gmail.com (S.N.); Asifjavead120@gmail.com (A.J.); hasnainsaeed420@gmail.com (M.H.S.) \\ 2 Department of Civil Engineering, NFC Institute of Engineering and Technology, Multan 66000, Pakistan; \\ ahsanrehman@nfciet.edu.pk \\ * Correspondence: syyed.adnanraheelshah@uhasselt.be; Tel.: +92-300-791-4248
}

Received: 4 February 2020; Accepted: 5 March 2020; Published: 8 March 2020

check for updates

\begin{abstract}
During the development of symmetric asphalt concrete material samples, aggregates play a vital role in the performance of its production. Shape characteristics and aggregates geology are two major factors influencing strength parameters of the asphalt concrete mix. In this study, two different geological sources of aggregates with different shape characterizations have been utilized for the development of the asphalt concrete mix. In addition to that, the stability analysis has been performed under different temperature conditions ranging between 25 and $60^{\circ} \mathrm{C}$. By the application of the destructive technique (DT) and non-destructive technique (NDT), the performance of the asphalt concrete mix has been analyzed and compared based on the geology of aggregates under various temperatures. Furthermore, a statistical model has been developed to analyze the stability and performance of the developed asphalt concrete mix with reference to regional climatic conditions. This study will help in the development of symmetric formation of sustainable asphalt materials.
\end{abstract}

Keywords: symmetry; mechanical properties; sustainability; materials; temperature

\section{Introduction}

Asphalt concrete most known as the flexible pavement is a composite material made up of fine aggregate, coarse aggregate, a filler material, and a bitumen binder. The proportioning of ingredients generally involves the selection of aggregates, asphalt and mineral additives to be used for the production of the bituminous mix [1]. Therefore, it is necessary to determine the basic properties of an individual constitutes that comprise the mixture. Aggregates play an important role as it contributes $95 \%$ in hot mix asphalt by weight [2]. Aggregates have commonly used material for construction projects such as road surfaces, making concrete, railway ballast, paving, and partition blocks. Hence, the selection of aggregates offers enhanced opportunity to improve pavement performance and durability in asphalt concrete [1]. An aggregate is a chemically inactive material that is mixed with a different binding material to develop concrete or mortar. Resistance to road evenness is the basic parameter that reflects the performance of the road surface and provides smooth traffic flow easiness [3]. The Geological Society, London (1993) defines aggregates as the rock particles that, when united in a 
bound and unbound condition come from part of or the whole engineering or building structure [4]. The mechanical performance of an aggregate in asphalt pavement has been studied in previous research and presented an approach to find out its response of an unbound coarse aggregate [5]. Damages to highways mostly takes place on surface roads, one of the main reasons is the weakness of a bond between the bitumen binding and the aggregates. Thus, a bond should be enhanced and to improve the antistripping properties of asphaltic concrete. Stripping is the phenomenon of surface tension between the aggregates and binder. The failure of the asphalt pavement due to several distress such as rutting on the variation of rut depth due to traffic load have been studied using statistical analysis [6]. The several types of distress including creep, rutting, shoving, cracking, and low stability are resulting in stripping due to the ingredient's compatibility. When the ingredients are used in correct proportions, they provide the best-expected service quality $[7,8]$. The performance of asphalt concrete by using the design method and rehabilitation timing and the result revealed that the road surface was greatly influenced due to traffic load and environmental conditions [9]. The temperature effect is also a key factor that has a direct influence on the viscosity of bitumen, which affects its ability to bond and provide adequate bonding for aggregates in Hot Mix Asphalt (HMA) paving mixes. Therefore, the performance of the asphalt mixture under the effect of increasing and decreasing temperatures is needed to be studied. Low stability in the asphalt mixture leads to various types of distress [10,11]. The maximum load resisting by the specimen before failure is the stability strength of that specimen. An arrangement of the Marshall test [12] is like an indirect tensile strength test [13], but the sample placed in the Marshall test head is within a certain limit. So, the Marshall stability is linked with the tensile strength of the specimen [14]. The stability of asphalt pavement relies on different parameters such as bitumen content, grade, aggregate size, traffic load, environment temperatures, etc. [15]. A fast and effective method has been developed to analyzed the elastic behavior of the top layer of the road surface [16]. The stability of asphalt concrete can be analyzed by the application of Marshall stability [17] and ultrasonic pulse velocity methods [18]. Marshall stability is an extensively used method throughout the world, which is although an insurmountable limitation, expensive and time-consuming process $[19,20]$.

The non-destructive technique (NDT) has one of the most reliable methods to determine the expected quality of the constructed pavement. The ultrasonic pulse velocity technique consists of measuring the time of travel through an ultrasonic wave, passing through the asphalt surface layer frequently [21]. Asphalt behavior was observed in the laboratory environment at low temperatures. A review of earlier studies indicated statistically strong relations between bitumen rheology and asphalt behavior at low temperature in the asphalt mixture [22]. In the literature, triaxial and stress relaxation tests was performed to predict the mechanical characteristics of the asphalt mixture under varying temperature conditions temperatures and confining pressures $[23,24]$. Asphalt strength was significantly affected under various temperatures. The viscosity and ductility of bitumen both are increased with a rise in temperature resulting in decreased stability. Hence, the performance of the HMA mixture has been shown a strong relationship between mixing and compaction temperature [25]. Therefore, it is important to know the impact of aggregate geology on asphalt concrete under varying temperature conditions.

In this research, two different geological sources of aggregates with different shape characterizations have been utilized for the development of the asphalt concrete mix. In addition to that, the stability analysis has been performed to predict the selection of the aggregate with respect to geology for asphalt mix production under different temperature conditions ranging between 25 and $60^{\circ} \mathrm{C}$. Using destructive (Marshall stability) and non-destructive (ultrasonic pulse velocity) techniques, asphalt concrete mix quality was analyzed and measured at different temperatures based on aggregate geology. This relationship has not been investigated before under varying temperature conditions. Furthermore, a statistical analysis has been done to predict the stability and performance of a prepared bituminous mix. This research also helps to increase the overall performance of the asphalt mix by choosing the aggregates based on geology in mega road construction. 


\section{Materials and Methods}

The complete research methodology is illustrated stepwise as shown in Figure 1, for the experimentation and detailed evaluations of asphalt mix properties.

Step 1: Selection of the basic materials and mix design.

Step 2: Selection of two types of aggregate with reference to geology, i.e., Sargodha is composed of Dolerite-sandstone and Sakhi Sarwar is composed of mixed limestone (55\%) and sandstone (45\%).

Step 3: Testing of basic properties of bitumen and aggregates.

Step 4: Trial mixing to calculate optimum binder content and testing.

Step 5: Development of the final mix design under varying temperature conditions, i.e., $\left(25^{\circ} \mathrm{C}, 30^{\circ} \mathrm{C}\right.$, $45^{\circ} \mathrm{C}$, and $60^{\circ} \mathrm{C}$ ) shown in Figure 1.

Step 6: Stability of asphalt samples and testing by Marshall stability (destructive test) and ultrasonic pulse velocity technique (non-destructive methods).

Step 7: Comparative performance analysis with reference to standards.

Step 8: Statistical analysis for the impact analysis of factors.

Step 9: Final decision making.

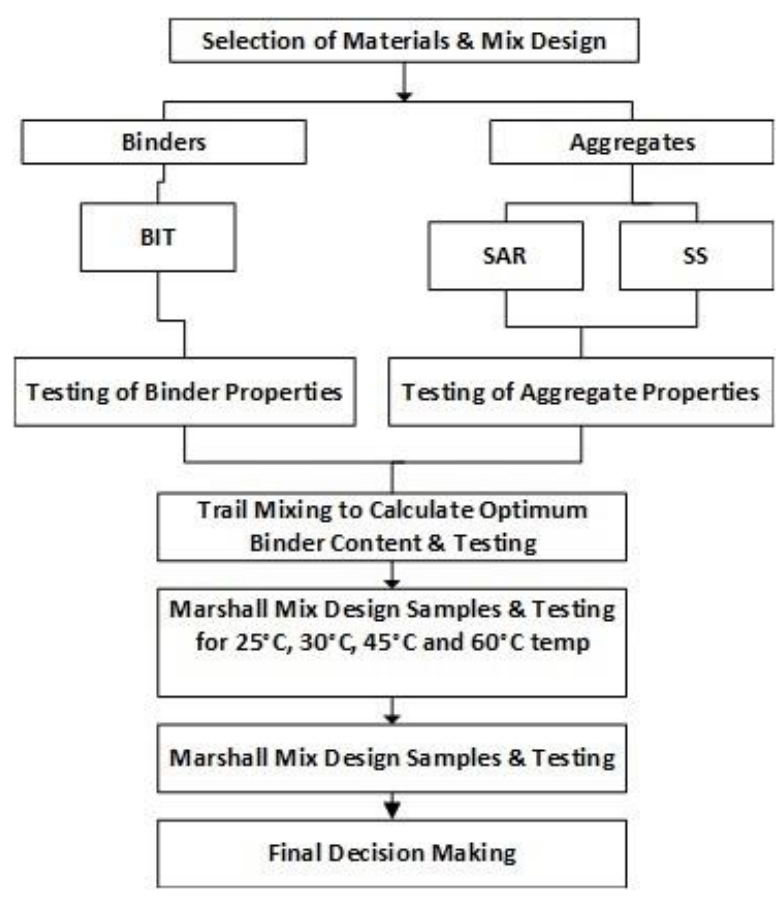

Figure 1. Research Framework.

\subsection{Bitumen}

Asphalt is a sticky, black, and highly viscous liquid or semi-solid form of petroleum [26]. It is commonly found in deep natural deposits or can be obtained after fractional distillation of crude oil when boiling at $525^{\circ} \mathrm{C}\left(997^{\circ} \mathrm{F}\right)$.

The primary use of bitumen $(70 \%)$ is for road surfaces where it is primarily used as a binder combined with aggregates. The utilization of the remaining bitumen $(30 \%)$ is for a number of vital applications such as in building construction, industry as a primary constituent of products [27-29]. Generally, bitumen is composed of hydrocarbon compounds and is effectively used as a waterproofing agent in paving and roofing applications [26]. The optimal binder percentage was $7 \%$ and the $60 / 70$ grade of bitumen was used in this study. All physicochemical properties of used bitumen were 
comprehensively evaluated and analyzed under the American Society for Testing and Materials (ASTM) standard and they have been given in Table 1. [30,31].

Table 1. Standard of testing bitumen properties and results.

\begin{tabular}{lllll}
\hline Type of Test & Test Method & Units & Results & Standard \\
\hline Penetration at $25{ }^{\circ} \mathrm{C}$ & ASTM D5-97 & $\mathrm{mm}$ & 66 & $60-70$ \\
Softening point & ASTM D36 & ${ }^{\circ} \mathrm{C}$ & 55 & $40-55$ \\
Flash Point & ASTM D92-16b & ${ }^{\circ} \mathrm{C}$ & 302 & $232 \mathrm{~min}$ \\
Ductility $25{ }^{\circ} \mathrm{C}$ & ASTM D113 & $\mathrm{cm}$ & 99 & $>75$ \\
\hline
\end{tabular}

\subsection{Aggregate}

Generally, aggregates comprise of $60-80 \%$ for the cake formation, so they must be carefully selected to achieve the desired strength. There are a wide variety of aggregate types currently being used around the globe. In the current studies, two types of aggregates with the geological nature of sandstone and limestone were used. Samples were cast for two types of aggregates such as Sakhi Sarwar (SS) and Sargodha (S) to determine the flow and stability values by destructive and non-destructive methods. Aggregate sizes ranging from 10 to $20 \mathrm{~mm}$ and fine grains with size $<4.75 \mathrm{~mm}$ were used that were obtained from Lawrencepur, Punjab. In addition, mechanical testing and examination were performed efficiently to analyze all aggregate properties and comparative standards also mentioned in Table 2 [32].

Table 2. Standards for testing aggregate properties (Sargodha and Sakhi Sarwar Crush).

\begin{tabular}{ccccc}
\hline Type of Test & \multicolumn{2}{c}{ Test Methods } & Result & Specifications \\
\hline & & SAR & SS * & \\
\hline Aggregate Impact Test & BS812:Part3 & $16.55 \%$ & $21.33 \%$ & Less than $27 \%$ \\
Los Angeles Abrasion Test & ASTM: C131 & $21.67 \%$ & $27 \%$ & Less than $35 \%$ \\
Aggregate Crushing Test & BS812: Part3 & $24.86 \%$ & $23.21 \%$ & Less than $30 \%$ \\
Water Absorption Test & ASTM:C127 & $2.50 \%$ & $1.90 \%$ & Less than $2 \%$ \\
Specific Gravity (Aggregate) & ASTM:C127 & 2.3 & 2.33 & $2-3$ \\
Geology & & SAR-Sand & SS-Lime and sandstone & \\
\hline
\end{tabular}

${ }^{*}$ Note: SAR (Sargodha Crush) and SS (Sakhi Sarwar Crush).

\subsection{Preparation of the Sample}

The Marshall test specimens were prepared with both types of aggregates, i.e., Sakhi Sarwar and Sargodha for comparative analyses of results by destructive and non-destructive methods. Approximately $1200 \mathrm{gm}$ of aggregate and filler were carefully taken from the basic prepared blend (see Table 3) and heated at a temperature in the range of $150-170{ }^{\circ} \mathrm{C}$. The specified grade of bitumen was heated at a temperature ranging between 160 and $170^{\circ} \mathrm{C}$. The heated aggregates and bitumen of the predetermined amount were then thoroughly mixed at a temperature of $165^{\circ} \mathrm{C}$ for $60 / 70$ grade of bitumen. The mixing was done with an asphalt mixer available in the Transportation Laboratory of Civil Engineering Department to achieve a homogenous mix. The different sizes of aggregates were taken in the desired proportion and a predetermined amount of bitumen was added to them. The mixture is a transfer into the mold and compacted by a standard hammer with 75 blows on both sides of the sample at a temperature in the range of $100-140^{\circ} \mathrm{C}$. The hydraulic sample extractor was used to demold the samples and specimens were then placed in a thermostatically controlled water bath at a standard temperature of $60^{\circ} \mathrm{C}$ from 30 to $40 \mathrm{~min}$ before the testing process began. Other specimens are also prepared according to standards and placed in a thermostatically controlled water bath at varying temperatures such as $25^{\circ} \mathrm{C}, 30^{\circ} \mathrm{C}$ and $45^{\circ} \mathrm{C}$ from 30 to $40 \mathrm{~min}$. The specimens then were tested in the Marshall stability machine to compare the stability and flow values of the samples. 
Table 3. Aggregate gradation for bituminous mixes.

\begin{tabular}{lcccccccc}
\hline Sieve Size (mm) & 19 & 12.5 & 9.5 & 4.75 & 2 & 0.475 & 0.177 & 0.075 \\
\hline Passing (\%) by Weight & 5 & 20 & 25 & 15 & 10 & 10 & 8 & 7 \\
\hline
\end{tabular}

\subsection{Experimental Methods}

\subsubsection{Ultrasonic Pulse Velocity Test}

The application of NDT has become a subject of interest in various countries. The NDT have used in many applications as it requires less cost and time. There are many studies in the literature that presented the use of NDT in different applications such as to find a defect in polymers and a metallic structure [33]. Among the available methods of NDT, ultrasonic pulse velocity has been effectively used for the detection of cracks in a concrete structure for many decades but in the literature, the use of this technology is not too much in the testing asphalt concrete [34-36]. The time of travel is measured electronically with a device when the ultrasonic wave is passed through the specimen. This test was done to assess the performance of concrete regarding uniformity, cracks, and deterioration of structures due to environmental conditions. The pulse velocity technique has been used to estimate the strength of concrete structures and various researchers have attempted to associate the relationship of pulse velocity with strength and other related properties of concrete. This test methodology is based to explore the fact that the propagation time expresses the density of the material, which is correlated with the compressive strength. By using the pulse velocity, it is also possible to verify the capacity or detect heterogeneous regions in the concrete [37]. The method is normally consisting of an electronic circuit that generating waves having a frequency range of $25-60 \mathrm{kHz}$.

Vibration-based techniques have been introduced to monitor the concrete structures in the 1930s. Canada [38] and England [39] developed non-destructive instruments at the same time. Canada developed the Soni scope whereas England developed an instrument called an ultrasonic tester. The ultrasonic pulse technique has become popular all over the world due to its simplicity [15]. A series of researches have been published on this subject [40,41]. The basic principle of ultrasonic pulse velocity is to measure the time necessary for the wave to propagate through the medium, which will depend on several factors such as the nature of the material and the presence of water in the pores, among others. The schematic diagram of the pulse velocity test was presented in the following Figure 2.

There are generally three types of waves that are produced, known as longitudinal waves, shear waves, and surface waves. These three waves travel with different velocities. The longitudinal waves travel with greater velocity. While the surface waves are the slowest. Ultrasonic pulse velocity (UPV) has been greatly influenced by the density and elastic properties of the materials [42]. In other words, a small cavity sample gives high pulse velocity reading, which indicates high stability and stability will be less for samples having more voids.

This study was proposed to explore the relationship between the bitumen qualities and Marshall stability of the asphalt concrete samples using ultrasonic pulse velocity. The time of travel between the surface of the asphalt core sample and the face of the transducer was measured electronically. Pulse velocity measurement is determined by the divided path distance to the time of travel. The battery-operated portable device was used in this study according to both Bs-1881-203 and ASTM C597-02 standards. The transmit time through the specimen is measured between the input and output of the waves with an accuracy of 0.1 microseconds and a $1.2 \mathrm{kV}, 500 \mathrm{~V}$ wavelengths. In order to use the ultrasonic pulse velocity (UPV) in concrete, it is recommended that a high pulse velocity reading gives an indication of good quality concrete [43]. Normally, the quality of construction materials is related to its rigidity. The UPV can also be used to measure other physical properties such as material nature, the porosity and the presence of emptiness or water in the pores system that 
influences the wave propagation. In the current study, ultrasonic pulse velocity was measured at a laboratory temperature called the 1st ultrasonic velocity of that sample.

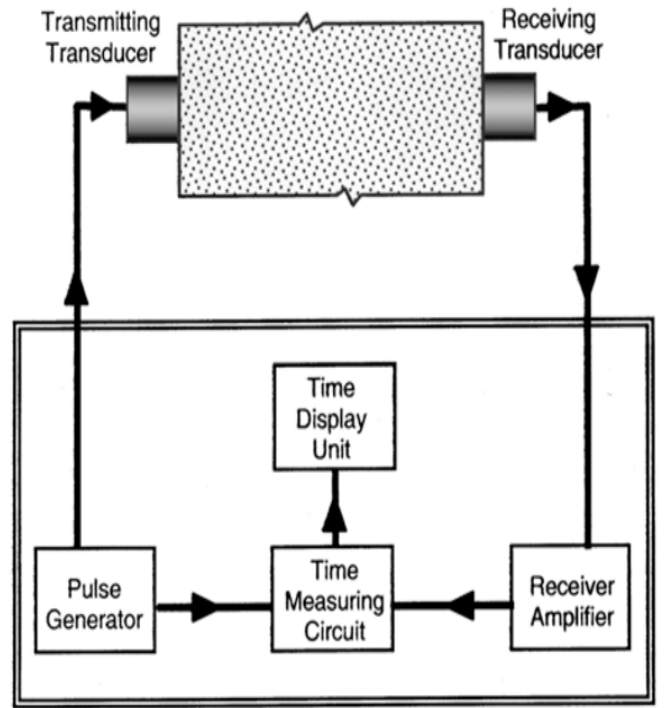

(a)

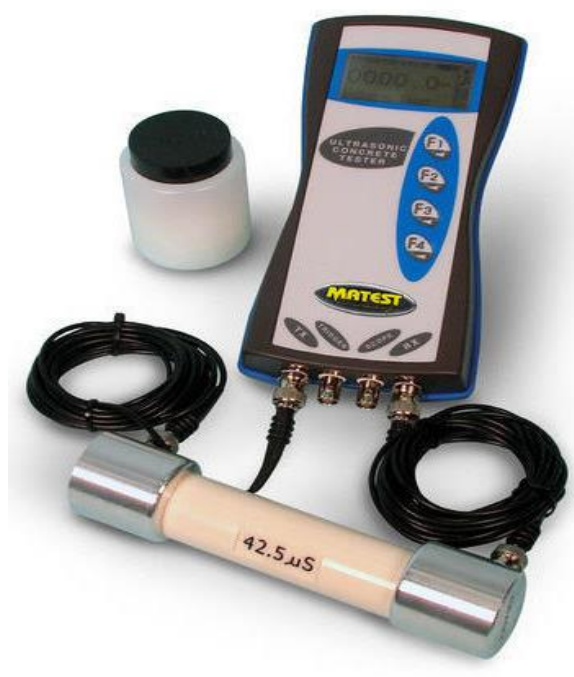

(b)

Figure 2. (a) Schematic overview of the ultrasonic pulse velocity test and (b) device.

\subsubsection{Stability Test}

Destructive (Marshall stability) and non-destructive (ultrasonic pulse velocity) testing was comprehensively done to determine the stability of samples under different temperature conditions ranging between 25 and $60{ }^{\circ} \mathrm{C}$. Marshall stability is defined as the maximum load in $\mathrm{KN}$ at a rate of $5 \mathrm{~mm} / \mathrm{min}$ deformation before failure of the sample. This method involves several significant limitations such as drilling, transporting, and testing equipment and personnel shown in Figure 3.
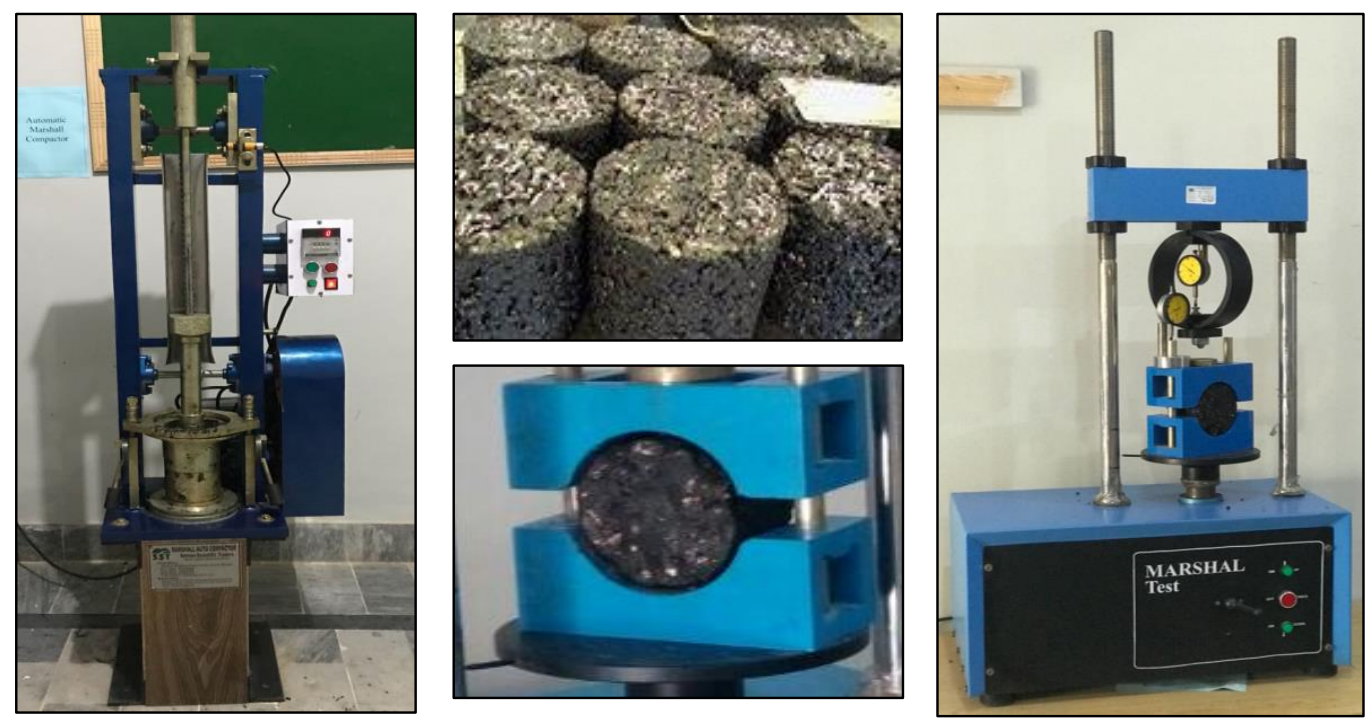

Figure 3. Marshall testing machine with asphalt specimen and compactor apparatus.

For these reasons, the ultrasonic pulse velocity technique was used to predict the stability of an in-service road surface as it requires less cost and time than destructive testing. Whereas Marshall stability gives more reliable results regarding the structure strength, the ultrasonic pulse velocity test is not as reliable but it is useful to analyze the concrete properties and to determine its homogeneity. 
The correlation between the NDT (using ultrasonic pulse velocity test) and DT (structure strength by Marshall stability test) could be established [44].

\section{Results and Discussions}

\subsection{Marshall Stability Analysis Based on Environment Temperature}

All samples were cast with two types of aggregates (Sakhi Sarwar and Sargodha) to analyze the relationship between stability and different temperatures conditions ranging between 25 and $60{ }^{\circ} \mathrm{C}$. The average stability and flow values of all two types of aggregate were considered for detailed analysis and results were shown in Figures 4 and 5. This study presents the analysis of least square regression using Microsoft Excel in order to explore the overall trends in the data. A significant relationship between stability and temperature was observed. The $R^{2}$ value obtained using the ANOVA analysis for both aggregate types shows a small deviation both for stability and the flow value under varying temperature conditions. It was also observed that the slope of the trend line for the samples casted with both types of aggregate is similar whereas the stability and flow value of Sargodha crush is quite better as compared to Sakhi Sarwar crush. In other words, the use of Sargodha crush in the development of asphalt concrete during road pavement minimized the influence of temperature.

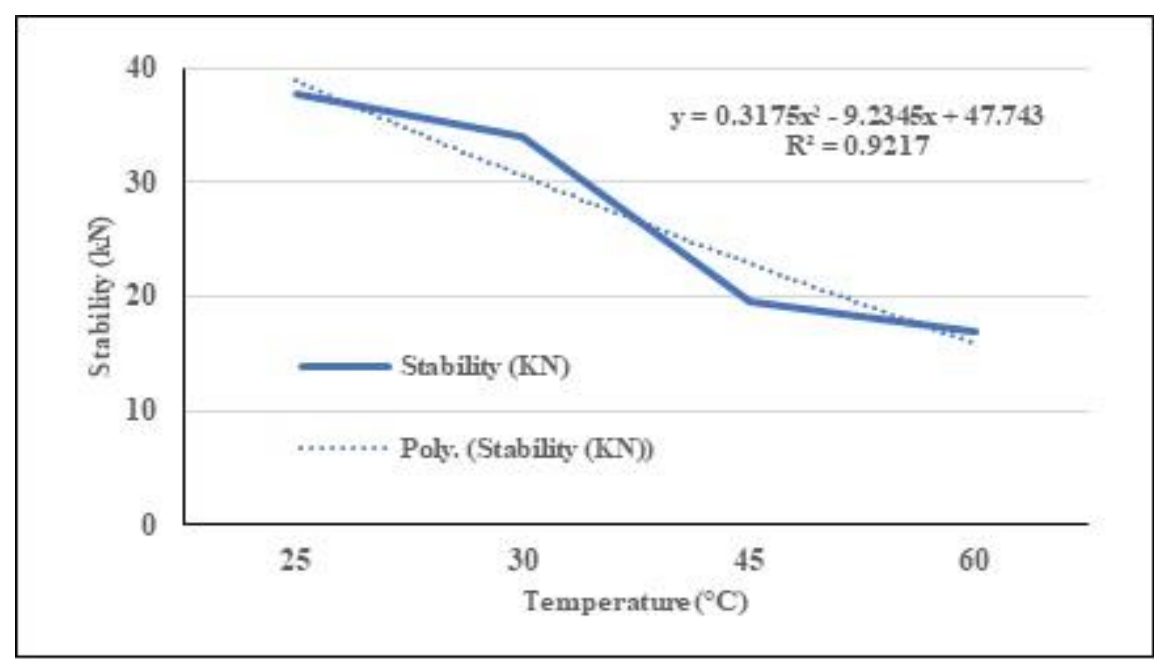

(a) Sargodha Crush (Sandstone)

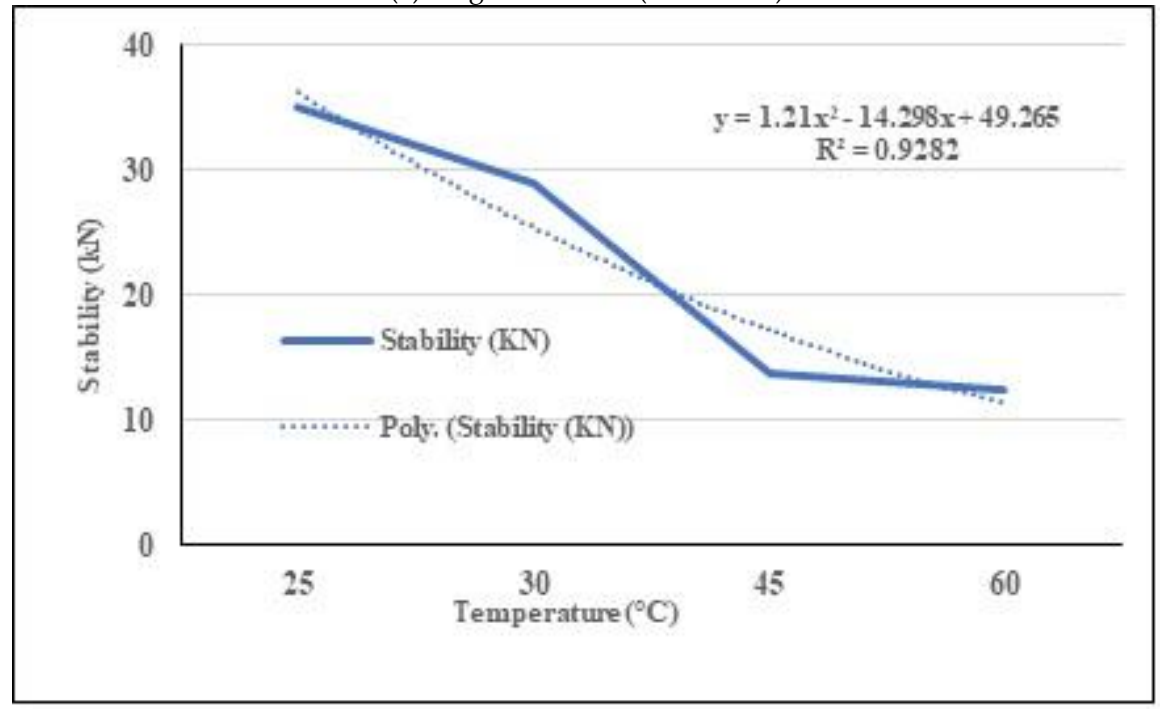

(b) Sakhi Sarwar Crush (Lime-Sandstone)

Figure 4. Stability Vs different temperature conditions for (a) Sargodha and (b) Sakhi Sarwar Crush. 


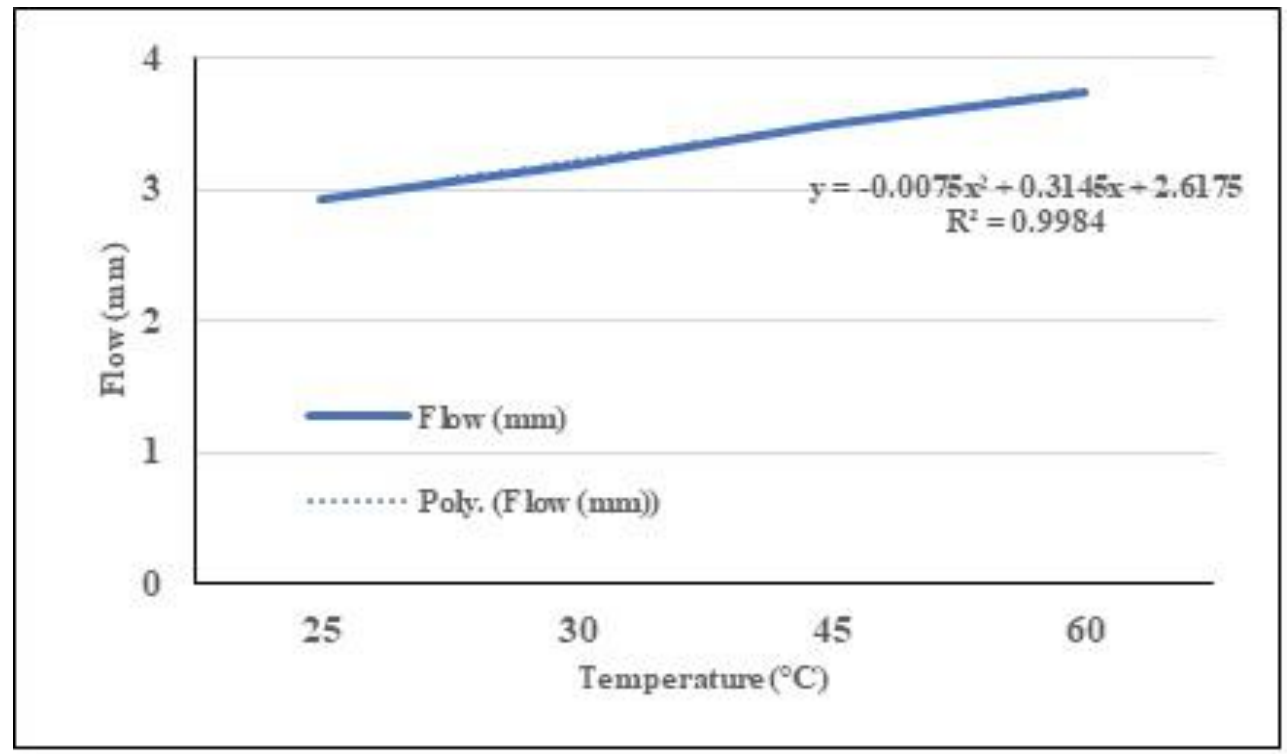

(a) Sargodha Crush (Sandstone)

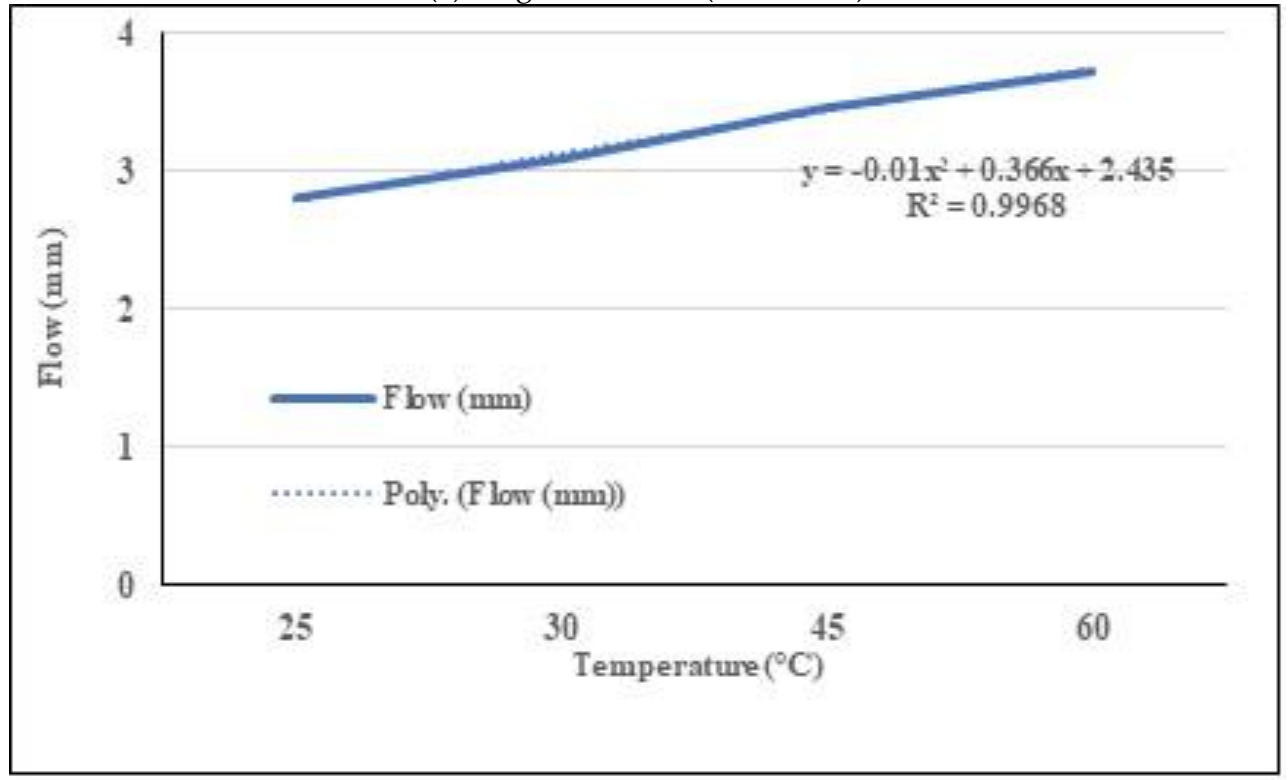

(b) Sakhi Sarwar Crush (Lime-Sandstone)

Figure 5. Average flow values based on different temperature conditions for (a) Sargodha and (b) Sakhi Sarwar.

The above figure shows that when the temperature was low, the value of stability was high and with increasing temperature, it will tend to decrease significantly. This is because viscosity was directly related to temperature. The increasing temperature had an indirect relation with the stability and direct relation with the flow values of the samples due to the fluidity of bitumen.

\subsection{Relationship between Stability and Ultrasonic Pulse Velocity}

Temperature has been given significant priority because it is closely related to road performance. At high temperature, bitumen exhibited viscoelasticity whereas at low temperature it showed elasticity. In Figure 6, the trend line shows the relationship between stability and ultrasonic pulse velocity with varying environmental conditions. The results from the graph indicate that with the increase in temperature, the stability and ultrasonic passing time decreased significantly. In addition to that, the passing time of ultrasonic pulse velocity was found to reduce under the influence of varying 
temperatures shown in Figure 6. The reason is that when the sample is exposed to high temperatures, the binder fills the gap between the internal voids due to fluidity.

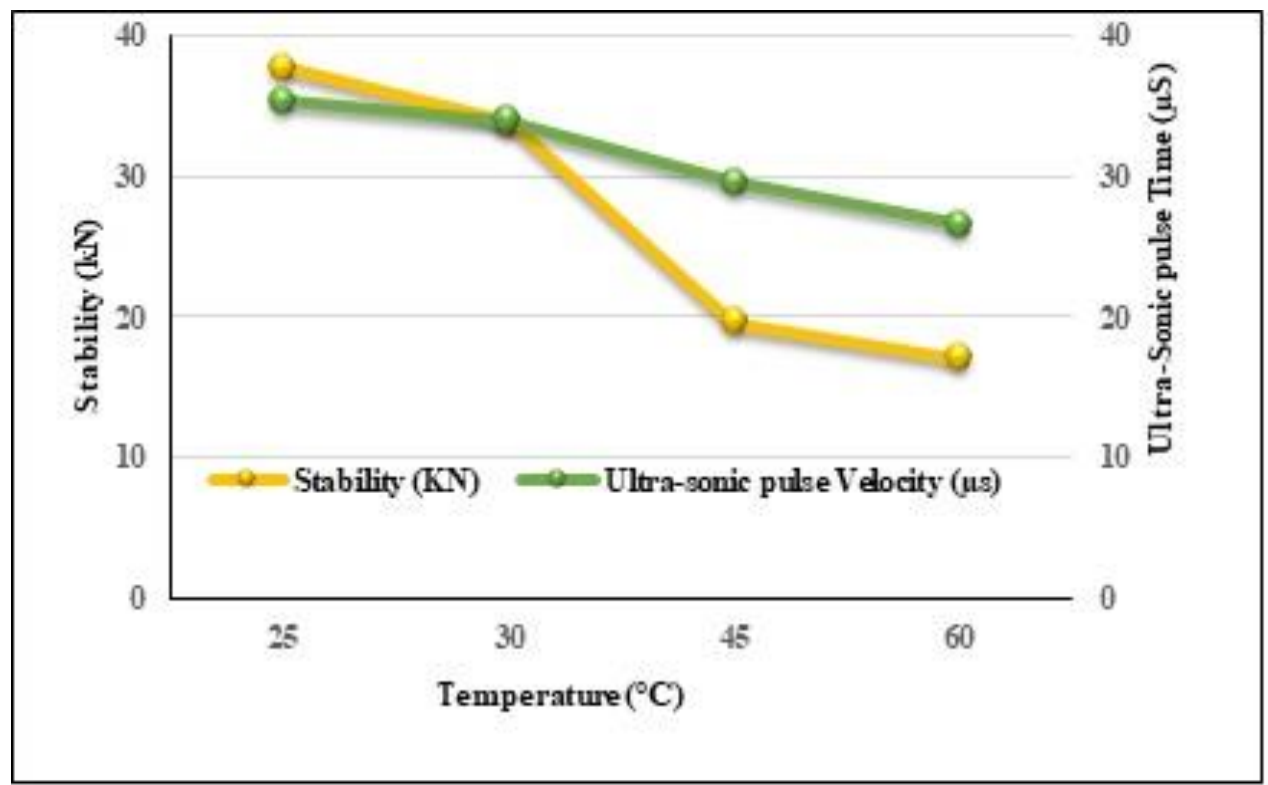

(a) Sargodha Crush (Sandstone)

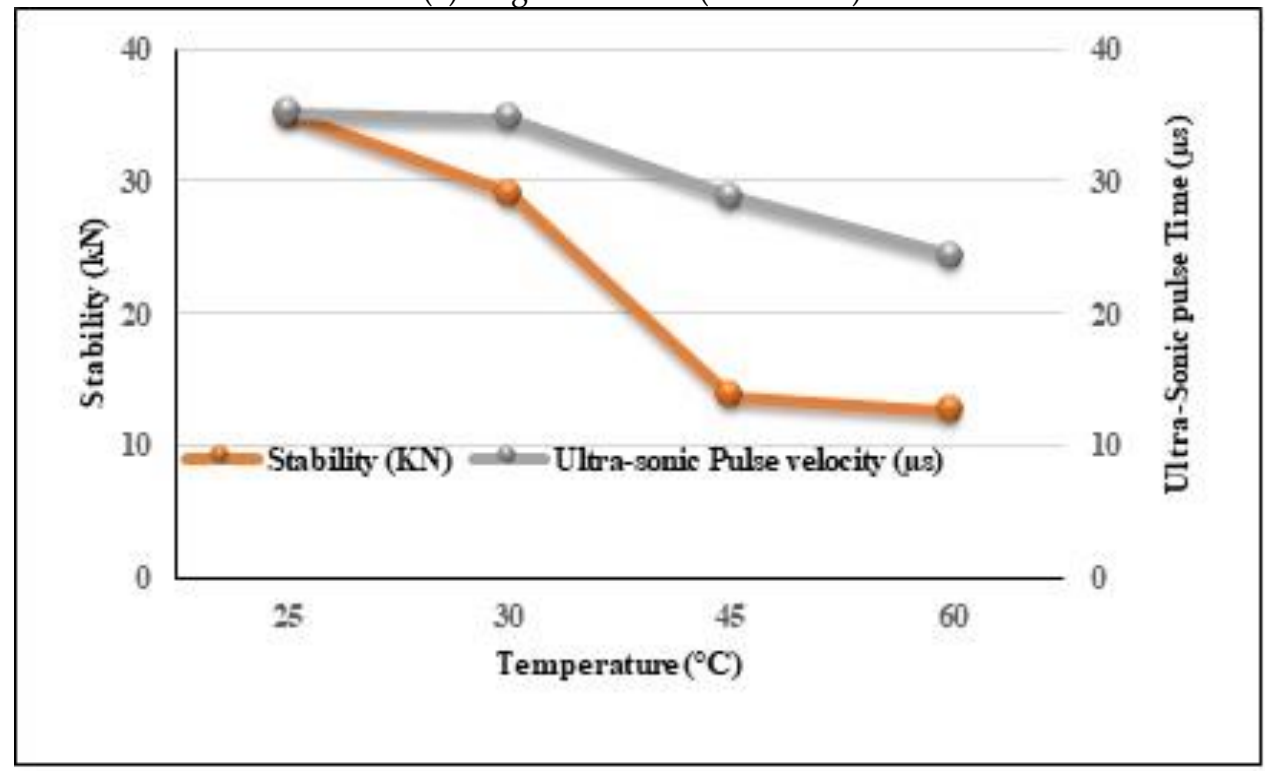

(b) Sakhi Sarwar Crush (Lime-Sandstone)

Figure 6. Average stability and second ultrasonic pulse time based on different temperature conditions for (a) Sargodha and (b) Sakhi Sarwar.

From the above figures, it is clearly observed that at $25^{\circ} \mathrm{C}$, the ultrasonic pulse velocity time was high and tended to decrease with the rise in temperature binder filling the gaps in the cavities due to fluidity. In other words, the speed of ultrasonic passing time was high when the cavities were less in the sample and vice versa because the travel speed of wave is much faster in air than in solids, i.e., aggregates. However, on the other hand, due to an increase in the softness of the binder under the influence of temperature the stability of the samples was found to reduce significantly 


\section{Conclusions}

In this study, a statistical analysis was performed on all the data obtained experimentally to compare the impact of different aggregate based upon their geology on the strength of the asphalt pavement under varying temperature. According to this research work, max strength was achieved at 25 and $30^{\circ} \mathrm{C}$ by employing both types of aggregates, i.e., Sargodha (sandstone) and Sakhi Sarwar (limestone and sandstone). In this research, the second degree of the polynomial was presented for each aggregate type, which helps other researchers and engineers to validate such parameters during decision making of higher performance parameters. The results for asphalt concrete mixes containing Sargodha crushed were having relatively well stability compared to Sakhi Sarwar crushed. This paper showed that ultrasonic pulse velocity is a very interesting method for damage detection of asphalt concrete that can easily be applied on site. It was observed that the stability of asphalt core samples has an indirect relation with ultrasonic passing time. This could clearly be observed with $60{ }^{\circ} \mathrm{C}$ of samples, which had the lowest stability and had the longest ultrasonic passing time as compared to other samples exposed to various temperatures. In addition, ultrasonic velocity decreased with an increase in voids when the sample was exposed to high temperatures. In other words, with the increasing of temperature, the stability of the asphalt mixes decreased significantly. The results of this study clearly show that when the temperature was low, the surface of the sample was affected only and the temperature inside the sample was not significantly affected by the bitumen. However, as temperature increasing bitumen is heated and inside the samples, the temperature increased too, which resulted in an increase in fluidity of bitumen. The strength of the asphalt mix was reduced due to increased viscosity and ductility. Consequently, premature distresses are developed on the road surface due to insufficient mixing and compaction temperature are some issues such as segregation, high air void content resulting in insufficient mixing, and compaction temperature. It should be observed that samples were subjected to heat from all four sides in this research, whereas in the highway the top surface of the road was exposed to heat only. Thus, to comprehend the real effect of temperature on roads, it is necessary to determine the behavior of asphalt's lower layers during the day need to be further studied. This finding could open a way towards decisions regarding the optimum thickness of the binder and erosion layers, thus improving the stability and performance of asphalt concrete in road construction. However, this research will also assist in analyzing the effect of source geology on road construction.

Author Contributions: Conceptualization, M.K.A. and S.A.R.S.; Data curation, A.N.S., M.U.S. and S.N.; Formal analysis, M.K.A., S.A.R.S., H.A., S.N. and M.H.S.; Investigation, A.J. and M.H.S.; Resources, A.J.; Software, S.N. and A.R.K.; Writing-original draft, M.K.A. and S.A.R.S.; Writing-review and editing, A.R.K. All authors have read and agreed to the published version of the manuscript.

Funding: This research received no external funding.

Conflicts of Interest: The authors declare no conflict of interest.

\section{References}

1. Brockenbrough, R.L.; Boedecker, K.J. Highway Engineering Handbook: Building and Rehabilitating the Infrastructure; McGraw-Hill: New York, NY, USA, 2003.

2. Aodah, H.H.; Kareem, Y.N.; Chandra, S. Performance of bituminous mixes with different aggregate gradations and binders. Int. J. Eng. Technol. 2012, 2, 1802-1812.

3. Celko, J.; Decky, M.; Kovac, M. An analysis of vehicle-road surface interaction for classification of IRI in the frame of Slovak PMS. Eksploat. Niezawodn. Maint. Reliab. 2009, 41, 15-21.

4. Fookes, P.G. Tropical Residual Soils: A Geological Society Engineering Group working Party Revised Report; Geological Society: London, UK, 1997.

5. Shashidhar, N.; Zhong, X.; Shenoy, A.V.; Bastian, E. Investigating the role of aggregate structure in asphalt pavements. In Proceedings of the International Center for Aggregates Research 8th Annual Symposium: Aggregates-Asphalt Concrete, Bases and Fines, Denver, CO, USA, 12-14 April 2000. 
6. Vaitkus, A.; Paliukaitè, M. Evaluation of time loading influence on asphalt pavement rutting. Procedia Eng. 2013, 57, 1205-1212. [CrossRef]

7. Roberts, F.L.; Kandhal, P.S.; Brown, E.R.; Lee, D.-Y.; Kennedy, T.W. Hot Mix Asphalt Materials, Mixture Design and Construction; National Asphalt Pavement Association: Lanham, MA, USA, 1991.

8. Ahmed, K.; Irfan, M.; Ahmed, S.; Ahmed, A.; Khattak, A. Experimental investigation of strength and stiffness characteristics of hot mix asphalt (HMA). Procedia Eng. 2014, 77, 155-160. [CrossRef]

9. Mikolaj, J.; Remek, L.; Macula, M. Asphalt Concrete Overlay Optimization Based on Pavement Performance Models. Adv. Mater. Sci. Eng. 2017, 2017. [CrossRef]

10. Tigdemir, M.; Karasahin, M.; Sen, Z. Investigation of fatigue behaviour of asphalt concrete pavements with fuzzy-logic approach. Int. J. Fatigue 2002, 24, 903-910. [CrossRef]

11. Tigdemir, M.; Kalyoncuoglu, S.F.; Kalyoncuoglu, U.Y. Application of ultrasonic method in asphalt concrete testing for fatigue life estimation. NDT E Int. 2004, 37, 597-602. [CrossRef]

12. Movilla-Quesada, D.; Raposeiras, A.; Silva-Klein, L.; Lastra-González, P.; Castro-Fresno, D. Use of plastic scrap in asphalt mixtures added by dry method as a partial substitute for bitumen. Waste Manag. 2019, 87, 751-760. [CrossRef]

13. Jiang, Y.; Deng, C.; Li, Q.; Liu, H. Effect of compaction methods on physical and mechanical properties of asphalt mixture. J. Mater. Civ. Eng. 2019, 31, 04019075. [CrossRef]

14. Chen, W.-F.; Liew, J.R. The Civil Engineering Handbook; CRC Press: Boca Raton, FL, USA, 2002.

15. Hannachi, S.; Guetteche, M. Review of the ultrasonic pulse velocity evaluating concrete compressive strength on site. In Proceedings of the Scientific Cooperation International Workshops on Engineering Branches, Istanbul, Turkey, 8-9 August 2014.

16. Lytton, R.L. Determining Asphaltic Concrete Pavement Structural Properties by Nondestructive Testing; Transportation Research Board: Washington, DC, USA, 1990.

17. Baldo, N.; Manthos, E.; Pasetto, M. Analysis of the Mechanical Behaviour of Asphalt Concretes Using Artificial Neural Networks. Adv. Civ. Eng. 2018, 2018, 17. [CrossRef]

18. Sarsam, S.I.; Kadium, N.S. Feasibility of Using Pulse Velocity to Evaluate Asphalt Concrete Properties. J. Adv. Civ. Eng. Constr. Mater. 2018, 1, 51-63.

19. Vila-Cortavitarte, M.; Lastra-González, P.; Calzada-Pérez, M.Á.; Indacoechea-Vega, I. Analysis of the influence of using recycled polystyrene as a substitute for bitumen in the behaviour of asphalt concrete mixtures. J. Clean. Prod. 2018, 170, 1279-1287. [CrossRef]

20. Hasnain Saeed, M.; Shah, S.A.R.; Arshad, H.; Waqar, A.; Imam, M.A.H.; Sadiq, A.N.; Hafeez, S.; Mansoor, J.; Waseem, M. Sustainable Silicon Waste Material Utilization for Road Construction: An Application of Modified Binder for Marshall Stability Analysis. Appl. Sci. 2019, 9, 1803. [CrossRef]

21. Sztukiewicz, R. Application of ultrasonic methods in asphalt concrete testing. Ultrasonics 1991, $29,5-12$. [CrossRef]

22. Isacsson, U.; Zeng, H. Cracking of asphalt at low temperature as related to bitumen rheology. J. Mater. Sci. 1998, 33, 2165-2170. [CrossRef]

23. Krishnan, J.M.; Rajagopal, K. Triaxial testing and stress relaxation of asphalt concrete. Mech. Mater. 2004, 36, 849-864. [CrossRef]

24. Iwanski, M.; Chomicz-Kowalska, A. The effects of using foamed bitumen and bitumen emulsion in the cold recycling technology. In Proceedings of the 8th ICEE Environmental Engineering, Vilnius, Lithuania, 19-20 May; 2011; pp. 1089-1096.

25. Gudimettla, J.M.; Cooley, L.A.; Brown, E. Workability of Hot Mix Asphalt. Transp. Res. Record. 2004, 1891, 229-237. [CrossRef]

26. Raheel Shah, S.; Arshad, H.; Waqar, A.; Saeed, M.; Hafeez, S.; Mansoor, J.; Sadiq, A.; Malik, M. Saving Energy in the Transportation Sector: An Analysis of Modified Bitumen Application Based on Marshall Test. Energies 2018, 11, 3025. [CrossRef]

27. Caniato, M.; Bettarello, F.; Marsich, L.; Ferluga, A.; Sbaizero, O.; Schmid, C. Time-depending performance of resilient layers under floating floors. Constr. Build. Mater. 2016, 102, 226-232. [CrossRef]

28. Bitumen, S. The Shell Bitumen Industrial Handbook; Thomas Telford: London, UK, 1995.

29. Kemalov, R.A.; Kemalov, A.F.; Nam, F.K. Comprehensive analysis of electrochemical and structural-dynamic properties of bitumnious insulating materials. Indian J. Sci. Technol. 2016, 9. [CrossRef] 
30. Firoozifar, S.H.; Foroutan, S.; Foroutan, S. The effect of asphaltene on thermal properties of bitumen. Chem. Eng. Res. Des. 2011, 89, 2044-2048. [CrossRef]

31. Radziszewski, P.; Kowalski, K.J.; Krol, J.B.; Sarnowski, M.; Piłat, J. Quality assessment of bituminous binders based on the viscoelastic properties: Polish experience. J. Civ. Eng. Manag. 2014, 20, 111-120. [CrossRef]

32. ASTM C136-06. Standard test method for sieve analysis of fine and coarse aggregates; Annual Book of ASTM Standard: West Conshohocken, PA, USA, 2006. [CrossRef]

33. Caniato, M.; Bettarello, F.; Marsich, L.; Ferluga, A.; Sbaizero, O.; Schmid, C. Impulse response method for defect detection in polymers: Description of the method and preliminary results. Polym. Test. 2016, 55, $78-87$. [CrossRef]

34. Pan, W.-H.; Sun, X.-D.; Wu, L.-M.; Yang, K.-K.; Tang, N. Damage Detection of Asphalt Concrete Using Piezo-Ultrasonic Wave Technology. Materials 2019, 12, 443. [CrossRef]

35. Rao, S.K.; Sravana, P.; Rao, T.C. Experimental studies in Ultrasonic Pulse Velocity of roller compacted concrete pavement containing fly ash and M-sand. Int. J. Pavement Res. Technol. 2016, 9, 289-301. [CrossRef]

36. Mounier, D.; Di Benedetto, H.; Sauzéat, C. Determination of bituminous mixtures linear properties using ultrasonic wave propagation. Constr. Build. Mater. 2012, 36, 638-647. [CrossRef]

37. Hoła, J.; Bień, J.; Schabowicz, K. Non-destructive and semi-destructive diagnostics of concrete structures in assessment of their durability. Bull. Pol. Acad. Sci. Tech. Sci. 2015, 63, 87-96. [CrossRef]

38. abd WJ Cheesman, J.L. An Ultrasonic Method of Deterioration and Cracking in Concrete Structures. ACI J. Proc. 1949, 46. [CrossRef]

39. Jones, R. Testing of concrete by ultrasonic-pulse technique. In Proceedings of the Highway Research Board Proceedings, Washington, DC, USA, 13-16 January 1953.

40. Malhotra, V. Testing Hardened Concrete: Non-Destructive Methods, ACI Monograph No. 9, ACI; Iowa State University Press: Ames, IA, USA, 1976.

41. Qurashi, M.A.; Shah, S.A.R.; Farhan, M.; Taufiq, M.; Khalid, W.; Arshad, H.; Tayyab, M.; Shahzadi, G.; Waseem, M. Sustainable Design and Engineering: A Relationship Analysis between Digital Destructive and Non-Destructive Testing Process for Lightweight Concrete. Processes 2019, 7, 791. [CrossRef]

42. Davis, A.; Ansari, F.; Gaynor, R.; Lozen, K.; Rowe, T.; Caratin, H.; Heidbrink, F.; Malhotra, V.; Simons, B.; Carino, N. Nondestructive test methods for evaluation of concrete in structures. Am. Concr. Inst. Aci 1998, 228.

43. Dumoulin, J.; Ibos, L.; Marchetti, M.; Mazioud, A. Detection of non emergent defects in asphalt pavement samples by long pulse and pulse phase infrared thermography. Eur. J. Environ. Civ. Eng. 2011, 15, 557-574. [CrossRef]

44. Özgan, E. Determining the stability of asphalt concrete at varying temperature and exposure times using destructive and non-destructive methods. J. Appl. Sci. 2007, 7, 3870-3879. 